\begin{tabular}{|l|l|l|l|l|l|l|l|l|l|l|l|}
\hline & \multicolumn{4}{|c|}{ Journal Code } & \multicolumn{4}{|c|}{ Article ID } & Dispatch: 13.07 .12 & CE: Argonista, Karen Mae \\
\cline { 2 - 4 } & C & A & S & P & 2 & 1 & 2 & 6 & No. of Pages: 10 & ME: \\
\hline
\end{tabular}

Journal of Community \& Applied Social Psychology

J. Community Appl. Soc. Psychol., (2012)

Published online in Wiley Online Library

(wileyonlinelibrary.com) DOI: 10.1002/casp.2126

\title{
Meta-stereotypes, Social Image and Help Seeking: Dependency-Related Meta-stereotypes Reduce Help-Seeking Behaviour
}

\author{
JULIET R. H. WAKEFIELD ${ }^{1 *}$, NICK HOPKINS ${ }^{1}$ and \\ RONNI MICHELLE GREENWOOD ${ }^{2}$ \\ ${ }^{1}$ School of Psychology, University of Dundee, Scotland, UK \\ ${ }^{2}$ Department of Psychology, University of Limerick, Limerick, Ireland
}

\begin{abstract}
People who need help can be reluctant to seek it. This can be due to social image concerns. Here, we investigate if these concerns may be prompted by a salient negative meta-stereotype: the belief that one's group is judged negatively by another group. Specifically, we researched group members' help-seeking behaviour in the context of a dependency-related meta-stereotype. In a two-condition study $(N=45)$, we manipulated participants' belief that their national group was judged dependent by a significant out-group. We then examined their subsequent help-seeking behaviour on a real-world task. Participants whose social identity as a group member was salient showed greater reluctance to seek help when the meta-stereotype was made prominent compared with when it was not. This suggests that, in a context where social image and social identity concerns are relevant, group members are willing to sacrifice the possibility of accessing needed help in order to avoid confirming a negative stereotype of their group. The implications of these results for helping transactions and community development are discussed. Copyright ( 2012 John Wiley \& Sons, Ltd.
\end{abstract}

Key words: social image; help-seeking behaviour; social identity; meta-stereotypes

People often need help in order to realise their goals. However, accepting help can be difficult. As much sociological and anthropological work has revealed, the giving and receiving of help is not simply a function of individuals' resources and needs: such transactions can be imbued with all manner of meanings and can be a vehicle with which to negotiate status and authority (e.g. Mauss, 1990). Moreover, such considerations may lead to the refusal of help. Apparently during the 1992 famine in sub-Saharan Africa, villagers refused to unload their own consignment of emergency food unless paid to do

*Correspondence to: Juliet R. H. Wakefield, School of Psychology, University of Dundee, Dundee, DD1 4HN, UK.

E-mail: j.r.h.wakefield@dundee.ac.uk 
so (Carr, McAuliffe, \& MacLachlan, 1998). Although it is tempting to attribute such behaviour to greed, Carr et al. (1998) suggest that the villagers' request for payment may constitute an attempt to manage the loss of honour and dignity entailed in accepting such help. This more considered analysis of the African scenario involves appreciating the meanings of receiving help and what it says about one's identity and position in the world.

Our research seeks to contribute to understanding such issues through investigating the factors affecting group members' reluctance to seek needed help. Specifically, we focus on how concerns about how one's group is judged may impact upon group members' decisions to seek help.

\section{GROUP PROCESSES AND THE HELPING TRANSACTION}

Social Identity Theory maintains that groups are important in self-definition and that group behaviour entails processes that are not reducible to group members' idiosyncratic or personal attributes (Tajfel, 1981). It also proposes that group members seek a positively distinct in-group image, and recent social psychological work on group processes has begun to consider how such group image concerns may impact upon helping transactions.

Typically, such research focuses on how these concerns influence the provision of help to members of other groups. For example, van Leeuwen (2007) found that Dutch participants who experienced threat to the distinctiveness of their national identity were likely to advocate helping overseas tsunami victims in a 'Dutch' manner (e.g. sending Dutch royalty to affected regions). Help-giving can thus represent attempts to re-establish the positive distinctiveness of the in-group. Similarly, helping members of an out-group can be a means to re-inforce positive images of the group as warm (van Leeuwen \& Oostenbrink, 2005) and competent (van Leeuwen \& Täuber, 2011).

Comparatively less is known about how social identity and group image concerns are relevant to receiving help. Some work investigates the experience of being given an unrequested help. For example, Nadler and Halabi (2006) show that although high-status groups provide help to low-status groups to enhance or maintain their own position, members of the low-status group react negatively to receiving such help because it reinforces their inferiority. This was found to be especially true when the help was dependency oriented (i.e. help that emphasises recipients' inability to help themselves and undermines their sense of autonomy). More specifically, Nadler and Halabi found that participants receiving dependency-oriented help experienced lower affect and evaluated the out-group providing the help negatively.

However, we know very little about whether social identity concerns impede the seeking of needed help. Researching this question is important because it may help explain when and why people in need avoid seeking help, meaning their needs remain unmet. One factor likely to affect group members' help-seeking behaviour concerns the degree to which doing so would confirm a negative stereotype of their group.

\section{META-STEREOTYPES}

Community members are often concerned about their group's image in the eyes of others. Group members' beliefs about how their group is stereotyped by particular out-groups are termed meta-stereotypes (Vorauer, 2006), and such meta-perceptions can elicit various 
outcomes, the nature of which depends on the situational context and the specific stereotype in question. When performance on a stereotype-relevant task is being evaluated, there may be stereotype threat, where the group member performs badly because they are pre-occupied with fears of failure (e.g. Steele, 1997). In other contexts, in-group members may have more opportunity to act deliberately so as to avoid confirming the stereotype of their group. Our study addresses the latter scenario. That is, we are not concerned with how a meta-stereotype impacts upon participants' performance but instead wish to address the degree to which group members' beliefs about how they are stereotyped by another group may lead them to avoid confirming that stereotype by modifying a behaviour that is under their control: (not) asking for help.

\section{THE CURRENT RESEARCH}

Our research involves making participants aware that members of an out-group view their own group in terms of a specific negative stereotype. Or, to put this in another way, it involves making a particular negative meta-stereotype salient. Our study took place in Scotland, and we manipulated Scottish participants' understandings of how their national identity was judged by an important out-group: the English. Also, because of the merits of obtaining behavioural data (as opposed to intention or attitude-based data; for elaboration, see Wakefield et al., 2011; Hopkins et al., 2007), we measured participants' actual helpseeking behaviour during a problem-solving task.

To isolate the unique effects of meta-stereotyping on participants' help-seeking behaviour, we required a baseline control condition that involved all the components of the experimental condition but did not possess the meta-stereotype element. Because the key elements of the Meta-stereotype Salient condition entail participants thinking of themselves as Scots, thinking of the English as an out-group and thinking how the English view the Scots, we created a control condition with the first two features, but without the third feature (i.e. the meta-stereotyping element). This follows the logic of previous research investigating the impact of meta-stereotyping (Hopkins et al., 2007).

\section{DESIGN AND PREDICTIONS}

Our study involved two conditions. In the Meta-stereotype Salient (experimental) condition, we manipulated (and measured) how Scottish participants thought that the English stereotyped the Scots. Although neighbours, these nations share a history of rivalry and mutual stereotyping (e.g. Hopkins et al., 2007; for a discussion of the nature of this intergroup context, see Reicher \& Hopkins, 2001), and we used this relationship to encourage Scottish participants to consider the idea that the English perceive the Scots as 'handout dependent' (i.e. always taking but never giving). More specifically, we presented participants with dependency-related traits, such as scroungers and freeloaders, and asked them to rate the extent to which the English perceive the Scots in such terms.

In the Group (control) condition, Scottish participants reflected upon the same metastereotype-related traits but were only asked to consider their association with the Scottish in-group and the English out-group (i.e. participants rated the extent to which the Scots possessed each of the meta-stereotype-relevant traits and the extent to which the English possessed each of these traits). This meant that participants in the Group condition were 
encouraged to think about intergroup differences between the Scots and the English but were not encouraged to think about how the English perceive the Scots. As both the Group condition and the Meta-stereotype Salient condition therefore involved an intergroup context, between-condition differences in help-seeking levels could be attributed to meta-stereotype salience.

To deliver these manipulations and to enable participants' help seeking to be measured without the activation of demand characteristics, we employed a two-study cover story. More specifically, we presented participants with the manipulations in the 'first' study and measured their help-seeking during an apparently unrelated problem-solving task in the 'second' study (in which their Scottishness was not emphasised). One implication of such a design is that we need to consider the extent to which participants' sense of Scottish identity (made salient in 'Study 1') remained psychologically relevant in 'Study 2'. Indeed, the logic to this two-study design is that the effect of our manipulations should be most impactful for participants whose Scottish identity was salient during the help-seeking episode in 'Study 2'. As Scottish identity was made salient in both the experimental condition and the control condition, we did not expect to observe between-condition differences in this social identity salience variable, but we expected that participants' scores on this variable would moderate the effect of condition on help-seeking. That is, we predicted that those who saw themselves in terms of their Scottishness in 'Study 2' would seek less help when the English stereotype of the Scots as dependent was salient (Meta-stereotype Salient condition) compared with when it was not salient (Group condition).

We also measured participants' strength of Scottish identification so as to rule out the possibility that any effect of experimental condition on help seeking was mediated by our manipulations impacting on participants' identification strength.

\section{METHOD}

\section{Participants and design}

Female Scottish undergraduates $(N=45)$ were assigned randomly to two experimental conditions (Group, $n=21$ and Meta-stereotype Salient, $n=24 ; M_{\text {age }}=20.44$ years, $S D=4.22$, range: $17-37)$.

\section{Procedure}

Participants were tested individually and took part in what they believed were two separate studies. The 'first' allowed delivery of the manipulations; the 'second' allowed measurement of help-seeking.

Manipulations. Trait ratings.Manipulations were presented in the guise of a preliminary questionnaire that apparently investigated factors enhancing recall of English-related and Scottish-related traits (thereby creating a group context). In addition, participants in the Meta-stereotype Salient condition received a meta-stereotype prime (see succeeding text). 
To deliver these manipulations, participants received eight trait adjectives. Four represented the meta-stereotype (freeloaders, loafers, handout dependent and scroungers). Four were fillers not included in any analyses (clumsy, adventurous, friendly and creative).

Participants in the Group condition rated the extent to which they believed each trait belonged to the out-group stereotype (i.e. how much they believed the English possessed these traits; $0=$ strongly disagree and $4=$ strongly agree; $M=1.37, S D=0.72$, Cronbach's $\alpha=.73$ ). With the use of the same scale, those in the Meta-stereotype Salient condition rated the extent to which the English believed that the Scots possessed these traits $(M=2.05, S D=0.83$, Cronbach's $\alpha=.73)$. Then, and again using the same scale, participants in both conditions rated the extent to which they believed that the Scots possessed these traits (i.e. the auto-stereotype; overall $M=1.19, S D=0.73$, Cronbach's $\alpha=.79$ ). This meant that, in the Group condition, participants reflected on intergroup differences between the Scots and the English and that, in the Meta-stereotype Salient condition, participants reflected on how the English viewed the Scots. Most importantly, as four of the eight items represented the concept of dependency (e.g. scroungers), those in the Meta-stereotype Salient condition reflected on the idea that the English view the Scots as dependent.

Dependent measures. The dependent measures were presented in a separate study ('Study 2') of problem-solving behaviour during cooperative tasks. Participants believed that they were partnered with another student in a neighbouring room (who did not actually exist), and both would attempt a mystery-solving task independently. They could then request as much or as little help from each other as required. Requests were to be made on special forms, which would be swapped. Because help-seeking is perceived as less threatening when the source of help is deemed to be an expert in the area (Amato \& Saunders, 1985), we reasoned that presenting the helper as a fellow student (with no such expertise) would help to ensure that help-seeking was considered a threatening activity.

Partner identity. Participants completed a form requesting biographical information, including place of birth. This form was then apparently taken to the partner, and one from the partner is given to the participant (so the partners could learn more about each other). The partner's form contained (hand-written) information explaining that the partner had been born in London, grew up in Manchester and had come to this (Scottish) university because friends from Manchester were also studying here. The partner was therefore clearly English. To avoid gender effects, sex was not revealed.

Mystery task. Participants listened to a 3-minute long crime mystery story and were instructed to identify the criminal. To apparently help participants review the material relevant to solving the mystery, they were given $z$ minutes to complete seven mystery recall questions (based on the story; e.g. What was the name of the chief of police?). To ensure that participants could not answer all questions (providing a reason to seek help), four questions were unanswerable from the information provided. The other three were very difficult.

DV: Help-seeking. After $z$ minutes, participants received a consultation form on which they could indicate how much help they wished to seek from their partner on each recall question. For each question, participants could select one of four 'levels' of help: no help, a small hint, a large hint or a full answer. 
Evaluation form. Before the consultation forms were to be swapped, all participants completed a questionnaire. This supposedly analysed their experiences of the mystery task. In reality, it contained various additional measures. The extent to which participants' social identification as Scottish was salient in 'Study 2' was measured with a five-point single bipolar item, which asked participants to think about how they perceived themselves during the help-seeking episode. The question was introduced as follows: When I asked my partner for help, I felt that I was acting. ..; and one pole was anchored with completely as an individual (0), whereas the other was anchored with completely as a Scot (4); $M=0.80, S D=0.85$. Participants' strength of Scottish identification was also measured using four items from Hopkins et al. (2007; e.g. This national identity is very important to me; $0=$ disagree strongly and $4=$ agree strongly). These items were combined into a scale $(M=2.97, S D=0.78$, Cronbach's $\alpha=.81)$. Participants' affect was also measured but did not differ between conditions.

\section{RESULTS}

\section{Identification and social identity salience}

Participants' level of identification did not differ according to condition (Group condition: $M=3.10, S D=0.78$; Meta-stereotype Salient condition: $M=2.85, S D=0.79), t(43)=1.07$, $p=.29, d=0.32$. This indicates that any effects of the meta-stereotype manipulation on help-seeking were not due simply to participants in one condition identifying more strongly with their Scottish identity than participants in the other condition (i.e. identification did not mediate the effect of condition on help seeking).

As expected, the social identity salience variable was not affected by the manipulation (Group condition: $M=0.71, S D=0.78$; Meta-stereotype Salient condition: $M=0.87$, $S D=0.85), t(42)=-0.60, p=.55, d=-0.19$.

The measures of identification strength and social identity salience did not correlate ( $r=-.05, N=44, p=.74$ ), indicating that the social identity salience item did not simply measure identification strength.

\section{Perceived English stereotype endorsement}

Participants in the Meta-stereotype Salient condition indicated that the English perceived the Scots as significantly more handout dependent $(M=2.05, S D=0.83)$ than they themselves $\operatorname{did}(M=1.03, S D=0.72), t(23)=6.50, p<.001, d=1.31$, suggesting that participants believed the English to endorse the stereotype to a greater extent than they themselves did.

\section{Number of questions unanswered}

The number of questions left unanswered (out of seven) was equal across conditions (Group condition: $M=5.10, S D=1.00$; Meta-stereotype Salient condition: $M=4.92$, $S D=1.14), t(43)=0.56, p=.58, d=0.17$, indicating that participants in both conditions found the task equally difficult and experienced similar levels of need. 


\section{Help seeking}

Creating a help-seeking scale. To create a continuous help-seeking scale, we marked requests for no help as 0 , requests for small hints as 1 , requests for large hints as 2 and requests for full answers as 3. These were then summed to create a measure of help seeking. However, as participants were able to answer some questions themselves (without needing help), we also took this into account and obtained a measure (expressed in percentage form) that corresponds to the amount of help requested on those questions that participants could not answer themselves. On this scale, 0 would indicate that the participant sought no help on every question that they could not answer, and 100 would indicate that the participant sought full answers on every question that they could not answer (Wakefield, Hopkins, \& Greenwood, submitted a, b).

Levels of help seeking. The means for the help-seeking variable did not differ across conditions (Group condition: $M=72.32, S D=15.64$; Meta-stereotype Salient condition: $M=70.96, S D=14.24), t(43)=0.31, p=.76, d=0.09$. However, we expected the effect of condition on help-seeking to be moderated by the social identity salience variable. Accordingly, we conducted a regression analysis with condition as the independent variable and participants' social identity salience scores as the moderator variable. Both of these variables were standardised (Z-scores).

As predicted, the social identity salience variable moderated the effect of condition on help seeking, $R^{2}=0.15, \Delta R^{2}=0.15, F(1,40)=7.11, p=.011$.

Plotting this interaction at one standard deviation below (low) and above (high) the mean of the social identity salience variable showed that, as expected, for participants whose group membership was situationally salient during the help-seeking episode, help seeking was significantly lower in the Meta-stereotype Salient condition than in the Group condition (simple slope $=-6.53, S E=3.15, t=-2.07, p=.045$ ). The slope for participants whose group membership was relatively less salient showed no effect of condition (simple slope $=5.39, S E=3.08, t=1.75, p=.087$; Figure 1). To ensure the robustness of these results, we repeated the moderation analysis twice using different versions of the social

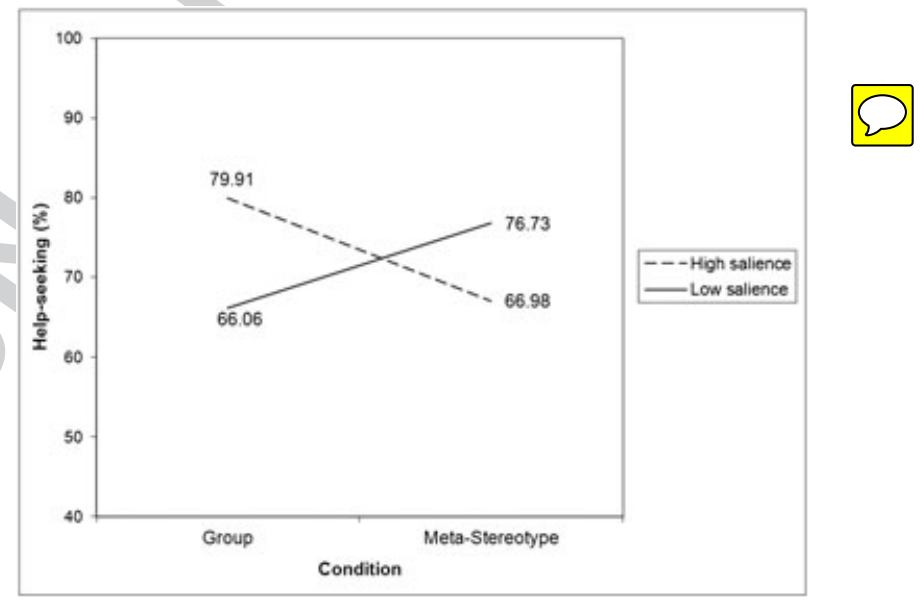

Figure 1. The moderating effect of participants' social identity salience on the relationship between condition and help seeking. 
identity salience variable. One of these involved converting the scores into a dichotomous version (high versus low), and the other involved a logarithmically transformed version. Both versions produced the same pattern of results as those reported earlier.

We also used the Johnson-Neyman technique (e.g. Hayes \& Matthes, 2009) to examine the specific values of the social identify salience variable at which the relationship between experimental condition and help-seeking became significant. As the social identity salience variable was standardised, its values ranged from -0.93 to 1.42 . The Johnson-Neyman analysis revealed that the relationship became significant $(p=.05)$ when the social identity salience value was 0.94 (coeff $=-6.17, S E=3.05, t=-2.02)$. The relationship between experimental condition and help seeking was non-significant below this value.

We also considered the possibility that the moderating effect of the social identity salience variable might have a stronger effect for participants who identified highly as Scots. However, regression analyses revealed the three-way interaction between condition, social identity salience and identification to be non-significant $(p=.38)$. This indicates that the moderating effect of the social identity salience variable was unaffected by participants' chronic Scottish identification strength.

\section{DISCUSSION}

Although we know something of the factors that motivate group members' attempts to negotiate how they are seen by others (e.g. Vorauer, 2006), we know less of the lengths to which group members may go in this regard and of the social costs they may be willing to incur. Helping transactions constitute a useful domain in which to investigate this issue. Work on helping shows that when faced with a stereotype of their group as mean, group members will disadvantage themselves, for example, through donating money (Hopkins et al., 2007). This hints at the sacrifices group members may make to avoid confirming a negative stereotype of their group. Yet, parting with already-possessed resources is one thing, and demonstrating that group members would avoid seeking needed help is another. Most obviously, it is costly because one's needs remain unmet.

The present data offer support for our hypothesis concerning the impact of social image concerns on help-seeking. Participants in the Meta-stereotype Salient condition believed that the English endorsed the stereotype of the Scots' dependency more than they themselves did. In turn, our helping data show that those in this condition who experienced relatively high levels of group salience during the help-seeking episode (and so saw themselves to be acting as group representatives) avoided seeking help when to do so would confirm a negative stereotype of the Scots. These results indicate that a negative meta-stereotype evokes responses in a way that a simple intergroup context does not.

As predicted, with regard to participants whose group membership was less salient in 'Study 2', we found no effect of condition. Intriguingly, the nature of the slope implies that such participants sought more help in the Meta-stereotype Salient condition than in the Group condition. Perhaps by failing to perceive the situation in intergroup terms, the image-related threat of help-seeking was attenuated for these participants, allowing them to seek high levels of help. Future work could investigate such possibilities. However, it bears repeating that this (non-predicted) trend was non-significant.

It should be noted that the mean values for the social identity salience variable in both conditions were somewhat low. This is perhaps unsurprising: when this variable was 
measured, participants were engaged in a problem-solving task ('Study 2') that apparently had nothing to do with the manipulations that preceded it ('Study 1'). Indeed, as they were presented with an individual task (solving the crime mystery), it is likely that participants would have been encouraged to think of themselves as an individual whose memory skills were being tested. Yet, although participants' responses on the social identity salience variable were generally low, we still found that the variability in participants' responses on this measure explained (moderated) the effect of condition on help-seeking.

It is also important to note that our manipulations were not found to have any effect on participants' identification strength (a result that would have suggested that changes in identification strength may have mediated the effect of condition on help-seeking). Moreover, participants' chronic identification strength was not found to affect the moderating influence of the social identity salience variable. Additionally, the pattern of results that we obtained with our moderating variable (social identity salience) remained constant when we treated it as a dichotomous variable (high versus low) and when we logarithmically transformed it. Our results therefore appear to be robust and to be genuinely bound up with issues of group identity salience and the belief that one's group is seen as dependent.

Inevitably, other issues raised by this work also require additional investigation. For example, it is important to note that only one specific meta-stereotype was made salient (in-group dependency). Many negative stereotypes entail notions of dependency (e.g. the idea that women are vulnerable and need men's help or that Black people are lazy and require White people's assistance), but there may be merit in investigating if group members avoid help seeking when faced with non-dependency-related meta-stereotypes. Another issue is whether group members are motivated to avoid confirming the stereotype because it relates to them as specific group members or because it relates to the in-group as a whole (Klein \& Snyder, 2003).

Yet, at the same time as requiring further research, our current results have wider significance: they help provide theoretical explanation for the reticence associated with real-world intergroup help receiving (Carr et al., 1998). In a world of crises and challenges, we need to understand how and why community members may refuse much-needed help. Most notably, although group memberships are important in terms of community development and empowerment, group members may be concerned about their group's image, and such concerns may lead to a reticence to seek help. Changing people's understandings of the helping transaction could be important in reducing such refusal, and our work suggests that group members' meta-stereotypes could be a useful site for intervention: if one could avoid dependency meta-stereotypes becoming psychologically prominent, group members' reluctance to seek help may be reduced. It may therefore be important for community workers not only to support the development of a strong group identity but also to consider community members' perceptions of how their community is perceived and judged by others.'

\section{REFERENCES}

Amato, P. R., \& Saunders, J. (1985). The perceived dimensions of help-seeking episodes. Social Psychology Quarterly, 48, 130-138. Article Stable URL: http://www.jstor.org/stable/3033608 Carr, S. C., McAuliffe, E., \& MacLachlan, M. (1998). Psychology of Aid. New York: Routledge. 
Hayes, A. F., \& Matthes, J. (2009). Computational procedures for probing interactions in OLS and logistic regression: SPSS and SAS implementations. Behavior Research Methods, 41, 924-936.

Hopkins, N., Reicher, S., Harrison, K., Cassidy, C., Bull, R., \& Levine, M. (2007). Helping to improve the group stereotype: On the strategic dimension of prosocial behavior. Personality and Social Psychology Bulletin, 33, 776-788.

Klein, O., \& Snyder, M. (2003). Stereotype confirmation and behavioral assimilation: From interpersonal to intergroup perspectives. In M. P. Zanna (Ed.), Advances in Experimental Social Psychology (pp. 153-234). San Diego, CA: Academic Press.

van Leeuwen, E. (2007). Restoring identity through outgroup helping: Beliefs about international aid in response to the December 2004 tsunami. European Journal of Social Psychology, 37, 661-671.

van Leeuwen, E., \& Oostenbrink, J. (2005). The effects of meta-stereotypes and audience on intergroup helping. Paper presented at the 14th General Meeting of the European Association for Experimental Social Psychology, Würzburg, Germany.

van Leeuwen, E., \& Täuber, S. (2011). Demonstrating knowledge: The effects of group status on outgroup helping. Journal of Experimental Social Psychology, 47, 147-156.

Mauss, M. (1990). The Gift: Forms and Functions of Exchange in Archaic Societies. London: Routledge.

Nadler, A., \& Halabi, S. (2006). Intergroup helping as status relations: Effects of status stability, identification, and type of help on receptivity to high-status group's help. Journal of Personality and Social Psychology, 91, 97-110.

Reicher, S. D., \& Hopkins, N. (2001). Self and Nation. London: Sage.

Steele, C. M. (1997). A threat in the air: How stereotypes shape intellectual identity and performance. American Psychologist, 52, 613-629.

Tajfel, H. (1981). Human Groups and Social Categories: Studies in Social Psychology. Cambridge: Cambridge University Press.

Vorauer, J. D. (2006). An information search model of evaluative concerns in intergroup interactions. Psychological Review, 113, 862-886.

Wakefield, J. R. H., Hopkins, N., Cockburn, C., Shek, K., Muirhead, A., Reicher, S., \& van Rijswijk, W. (2011). The impact of adopting ethnic or civic conceptions of national belonging for others' treatment. Personality and Social Psychology Bulletin, 37, 1599-1610.

Wakefield, J. R. H., Hopkins, N., \& Greenwood, R. M. (submitted a). Thanks, but no thanks: Women's help-seeking in the context of a dependency-related stereotype.

Wakefield, J. R. H., Hopkins, N., \& Greenwed, R. M. (submitted b). Help-seeking helps: Help-seeking and group image. 


\section{Author Query Form}

\section{Journal: Journal of Community \& Applied Social Psychology}

\section{Article: casp_2126}

\section{Dear Author,}

During the copyediting of your paper, the following queries arose. Please respond to these by annotating your proofs with the necessary changes/additions.

- If you intend to annotate your proof electronically, please refer to the E-annotation guidelines.

- If you intend to annotate your proof by means of hard-copy mark-up, please refer to the proof mark-up symbols guidelines. If manually writing corrections on your proof and returning it by fax, do not write too close to the edge of the paper. Please remember that illegible mark-ups may delay publication.

Whether you opt for hard-copy or electronic annotation of your proofs, we recommend that you provide additional clarification of answers to queries by entering your answers on the query sheet, in addition to the text mark-up.

\begin{tabular}{|c|l|c|}
\hline Query No. & \multicolumn{1}{|c|}{ Query } & Remark \\
\hline Q1 & $\begin{array}{l}\text { AUTHOR: Please check and confirm that the } \\
\text { hierarchy of section headings is correct. }\end{array}$ & \\
\hline Q2 & $\begin{array}{l}\text { AUTHOR: Please expand DV. } \\
\text { Q3 }\end{array}$ & $\begin{array}{l}\text { AUTHOR: Papers that have not yet been accepted } \\
\text { for publication should not be included in the } \\
\text { reference list; they should be cited in the text } \\
\text { only. Please update references "Wakefield, } \\
\text { Hopkins, \& Greenwood, submitted a and b" if } \\
\text { they have now been published. Use "in press" } \\
\text { (with journal title details, if appropriate) if they } \\
\text { have been accepted for publication. Otherwise, } \\
\text { remove them from the reference list and change } \\
\text { to "Wakefield, Hopkins \& Greenwood, } \\
\text { unpublished data" in the text. }\end{array}$ \\
\hline
\end{tabular}


Required software to e-Annotate PDFs: Adobe Acrobat Professional or Adobe Reader (version 7.0 or above). (Note that this document uses screenshots from Adobe Reader $\mathrm{X}$ )

The latest version of Acrobat Reader can be downloaded for free at: http://get.adobe.com/uk/reader/

Once you have Acrobat Reader open on your computer, click on the Comment tab at the right of the toolbar:

닙

This will open up a panel down the right side of the document. The majority of tools you will use for annotating your proof will be in the Annotations section, pictured opposite. We've picked out some of these tools below:

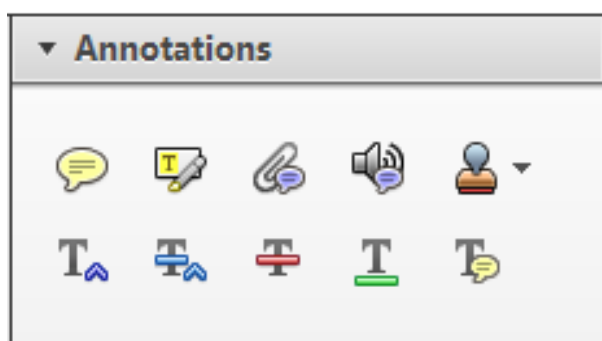

1. Replace (Ins) Tool - for replacing text.

Strikes a line through text and opens up a text box where replacement text can be entered.

How to use it

- Highlight a word or sentence.

- Click on the Replace (Ins) icon in the Annotations section.

- Type the replacement text into the blue box that appears.

Idard tramework for the analysis of $\mathrm{m}$ icy-Nevertheless, it also led to exog،

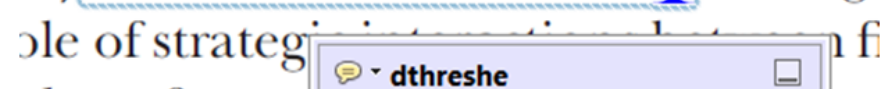
\begin{tabular}{l|l|l} 
aber of comp & 08/06/2011 15:58:17 & 0
\end{tabular} is that the $\mathrm{s} 1 \overline{\text {, which led }}$ of nain compo: be level, are exc nc

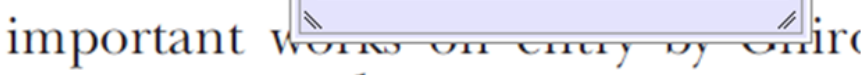
M heneferth) ${ }^{1}$ we anen the "hlarl $\mathrm{h}$

3. Add note to text Tool - for highlighting a section to be changed to bold or italic.

T Highlights text in yellow and opens up a text box where comments can be entered.

How to use it

- Highlight the relevant section of text.

- Click on the Add note to text icon in the Annotations section.

- Type instruction on what should be changed regarding the text into the yellow box that appears.

namic responses of mark ups ent with the VAR evidence

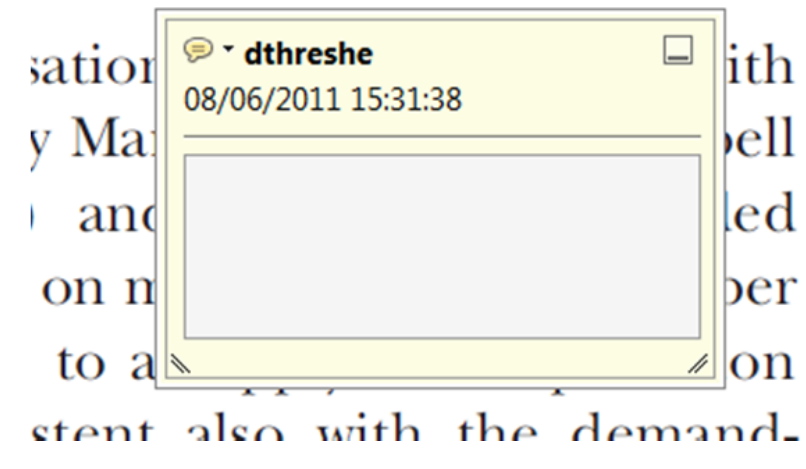

2. Strikethrough (Del) Tool - for deleting text.

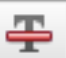

Strikes a red line through text that is to be deleted.

How to use it

- Highlight a word or sentence.

- Click on the Strikethrough (Del) icon in the Annotations section.

there is no room tor extra prohts al s ups are zero and the number of ret) values are not determined by Blanchard and Kiyotaki (1987), sfect competition in general equilil ts of aggregate demand and supply lassical framework assuming monol sen an evorenous number of firms

4. Add sticky note Tool - for making notes at specific points in the text.

Marks a point in the proof where a comment needs to be highlighted.

How to use it

- Click on the Add sticky note icon in the Annotations section.

- Click at the point in the proof where the comment should be inserted.

- Type the comment into the yellow box that appears.

iaisu airu suppiy sisuks. hivsl ui

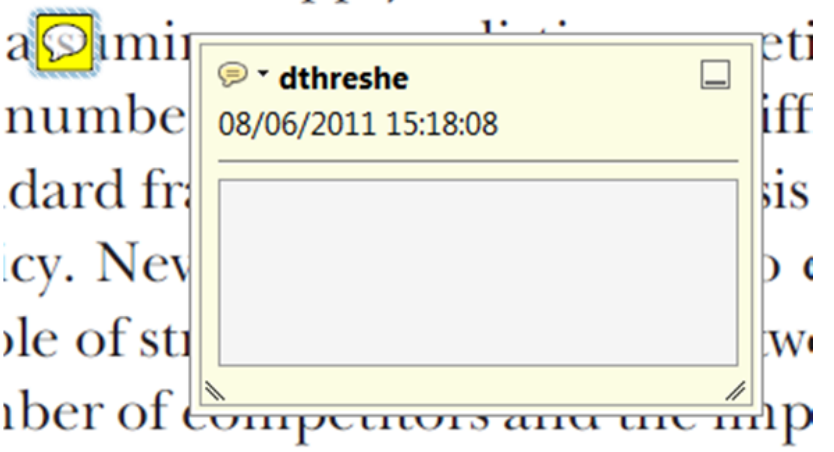

is that the structure of the sectc. 
5. Attach File Tool - for inserting large amounts of text or replacement figures.

Inserts an icon linking to the attached file in the appropriate pace in the text.

How to use it

- $\quad$ Click on the Attach File icon in the Annotations section.

- Click on the proof to where you'd like the attached file to be linked.

- Select the file to be attached from your computer or network.

- Select the colour and type of icon that will appear in the proof. Click OK.

E N D

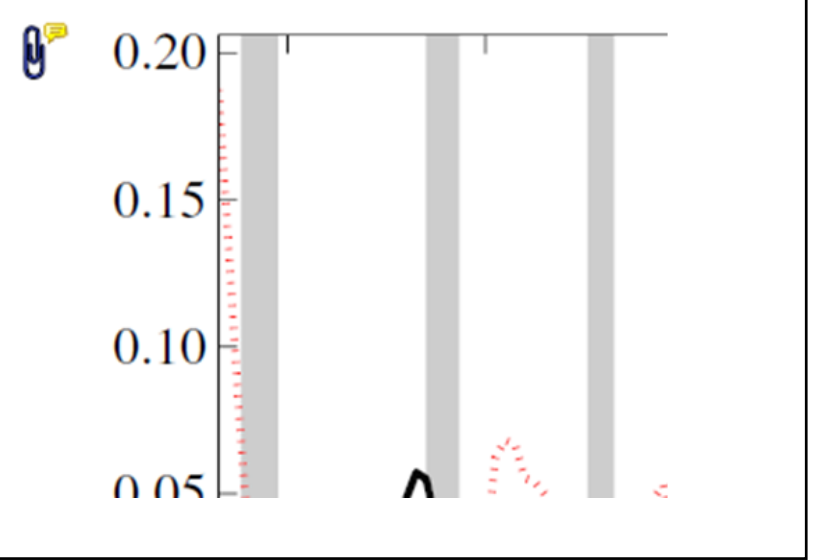

6. Add stamp Tool - for approving a proof if no corrections are required.

- Inserts a selected stamp onto an appropriate place in the proof.

\section{How to use it}

- $\quad$ Click on the Add stamp icon in the Annotations section.

- Select the stamp you want to use. (The Approved stamp is usually available directly in the menu that appears).

- Click on the proof where you'd like the stamp to appear. (Where a proof is to be approved as it is, this would normally be on the first page).

)t the Dusiness cycie, starting with the on perfect competition, constant ret

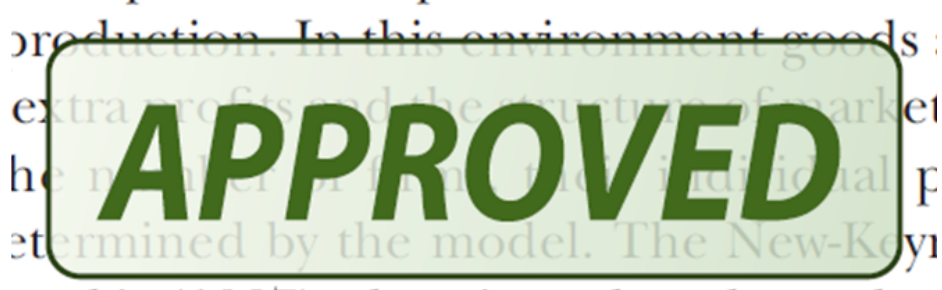
otaki (1987), has introduced produc general equilibrium models with nomin:

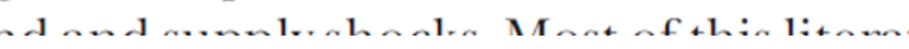

- Drawing Markups

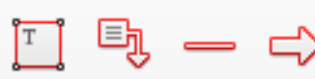

$0 \bigcirc \sqrt{6} \otimes$

\section{How to use it}

- Click on one of the shapes in the Drawing Markups section.

- Click on the proof at the relevant point and draw the selected shape with the cursor.

- To add a comment to the drawn shape, move the cursor over the shape until an arrowhead appears.

- Double click on the shape and type any text in the red box that appears.
7. Drawing Markups Tools - for drawing shapes, lines and freeform annotations on proofs and commenting on these marks.

Allows shapes, lines and freeform annotations to be drawn on proofs and for comment to be made on these marks.

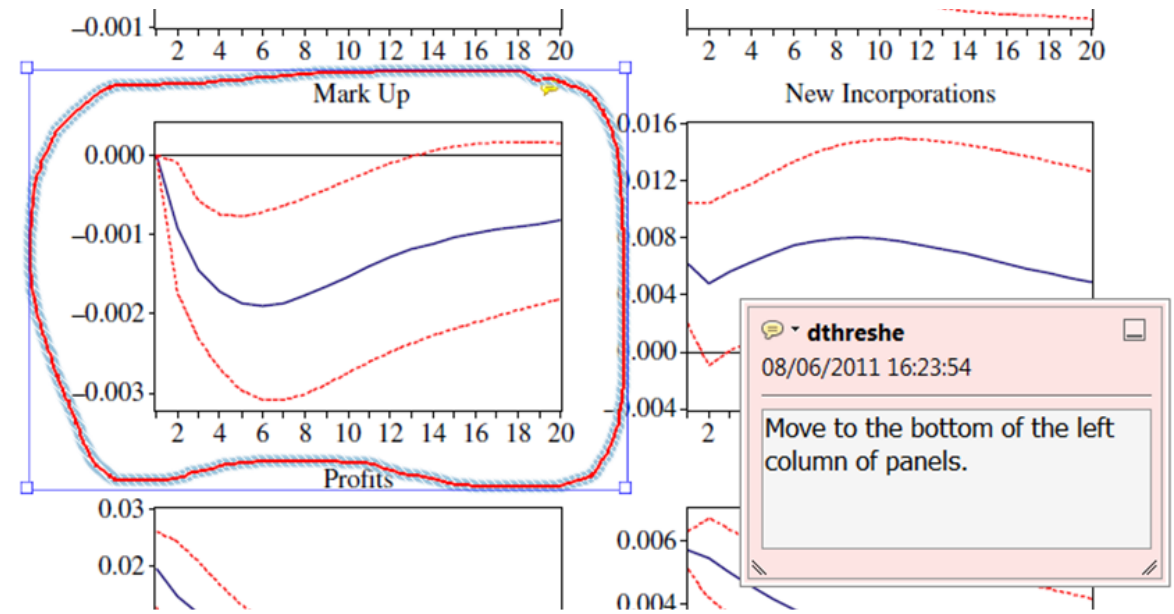

For further information on how to annotate proofs, click on the Help menu to reveal a list of further options:

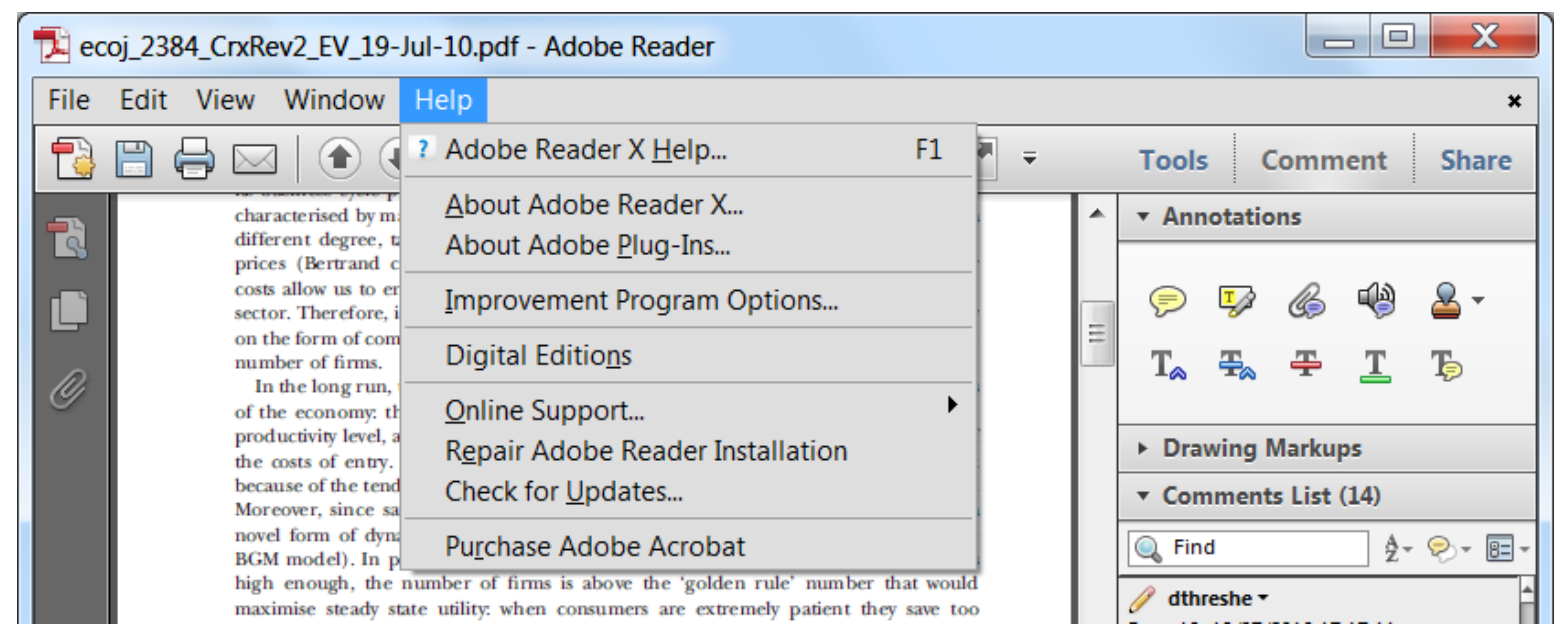

